\title{
Endothelial dysfunction assessment by noninvasive peripheral arterial tonometry in patients with chronic obstructive pulmonary disease compared with healthy subjects
}

\author{
Mario Malerba1 (i) | Alessandro Radaeli2 | Matteo Nardin'1 | Enrico Clini ${ }^{3}$ | \\ Giovanna Elisiana Carpagnano $^{4}$ | Edoardo Sciatti ${ }^{5}$ | Francesca Salghetti $^{5}$ | \\ Ivano Bonadei ${ }^{5}$ | Fabio Platto $^{5}$ | Enrico Vizzardi ${ }^{5}$
}

${ }^{1}$ Department of Internal Medicine, University of Brescia and ASST Spedali Civili, Brescia, Italy

${ }^{2}$ Department of Emergency ASST Spedali Civili, Brescia, Italy

${ }^{3}$ Department of Medical and Surgical Sciences, University of Modena-Reggio Emilia, Modena, Italy

${ }^{4}$ Department of Medical and Surgical Sciences, Institute of Respiratory Diseases, University of Foggia, Foggia, Italy

${ }^{5}$ Cardiology, Department of Medical and Surgical Specialties, Radiological Sciences and Public Health, University of Brescia, Brescia, Italy

\section{Correspondence}

Mario Malerba, Department of Internal Medicine, University of Brescia and ASST Spedali Civili, Brescia, Italy. Email: mario.malerba@unibs.it

\begin{abstract}
Introduction: Patients with chronic obstructive pulmonary disease (COPD) have an increased risk of cardiovascular disease. The endothelial dysfunction likely plays a central role in increasing cardiovascular risk.

Objectives: This cross-sectional, study investigated the prevalence and extent of endothelial dysfunction in patients with stable COPD.

Methods: Peripheral arterial tonometry (PAT) was measured by post-ischemic reactive hyperemia index (RHI) in 16 COPD patients, 16 healthy controls and 16 subjects with treated systemic arterial hypertension $(\mathrm{AH})$ and analysed with covariates condition (dyslipidemia, and medications).

Results: The prevalence of endothelial dysfunction was significantly higher in COPD group than in the other groups. Mean RHI was significantly lower in COPD patients compared with the other groups. At linear regression $\mathrm{FEV}_{1}$ and RHI were directly correlated (Spearman index $=0.553 ; P=.026$ ). COPD patients in groups $\mathrm{C}$ and $\mathrm{D}$ according to Global Initiative for Chronic Obstructive Lung Disease (GOLD) stages showed lower RHI compared with patients classified as A and $\mathrm{B}(P<.01)$. At multiple regression analysis the presence of dyslipidemia, COPD and AH were associated with the presence of endothelial dysfunction.
\end{abstract}

Conclusions: Endothelial dysfunction in stable COPD patients is probably implicated in the high cardiovascular comorbidity. This study suggests the potential utility of endothelial dysfunction evaluation in patients with COPD to a timely assessment and treatment for cardiac complications.

K E Y W O R D S

COPD, endothelial dysfunction, peripheral arterial tonometry, reactive hyperemia index

\section{1 | INTRODUCTION}

Chronic obstructive pulmonary disease (COPD) is a progressive disease of the lungs that is characterized by a persistent airflow limitation and is the third cause of morbidity and mortality worldwide. ${ }^{1}$ Patients with COPD have an increased risk of cardiovascular disease, and cardiac complications are among the leading causes of death in COPD patients. ${ }^{2}$ The mechanisms involved in the development of cardiovascular diseases in patients with a mainly lung disease are still being debate. Some factors involved in this relationship may be smoking, a shared risk factor between heart diseases and 
COPD and systemic inflammation associated with COPD. ${ }^{2}$ Furthermore, it is known that airflow obstruction profoundly affects cardiac function and gas exchange, leading to systemic consequences. An increased prevalence of ischemic heart disease and hypertension is seen in COPD patients and these conditions are linked to poor prognosis. ${ }^{3}$ Although the pathogenic mechanism that links COPD to vascular diseasesrelated is poorly understood, data have supported the potential contribution of vascular endothelial dysfunction and arterial stiffness. ${ }^{4}$ Endothelial dysfunction is commonly described as the inability of the artery to sufficiently dilate in response to an appropriate endothelial stimulus. Endothelial homeostasis is involved in regulation of vasomotor tone, regulation of vascular smooth muscle cell proliferation and migration, thrombogenesis and fibrinolysis. ${ }^{5}$

Previous studies have emphasized the importance of endothelial as a prognostic factor and an independent predictor of all-cause and cardiovascular mortality. ${ }^{2}$ COPD patients also frequently exhibit endothelial dysfunction which can be the main cause of cardiac comorbidities. ${ }^{6}$ The degree of endothelial dysfunction is proportional to disease severity measured by airway obstruction. ${ }^{7,8}$ Endothelial dysfunction can be assessed by different methods, the most widely utilized method is flow-mediated dilation (FMD) test, but is quite complex requiring the use of ultrasound, trained personal and is time consuming. Peripheral arterial tonometry (PAT) and pulse wave velocity (PWV) represent two noninvasive methods for assessing endothelial function at peripheral and central sites, respectively. PAT currently represents an easy, simple, noninvasive test to study endothelial function at the fingertip. ${ }^{9}$ The major novelty of the present study is the application of this noninvasive and reproducible finger plethysmography PAT to detect endothelial dysfunction in COPD patients. The aim of the study was to assess the prevalence and the degree of endothelial dysfunction in a group of stable COPD patients compared with a group of healthy subjects and a group of subjects with treated arterial hypertension ( $\mathrm{AH})$. A secondary purpose was to determine the relationship between the degree of endothelial dysfunction and airflow limitation in patients with COPD.

\section{2 | MATERIALS AND METHODS}

\section{1 | Study design}

This was a cross-sectional, observational, descriptive study. This study complied with the Declaration of Helsinki. It has approved by the local Review Board and each subject enrolled signed informed consent. The patients were enrolled between April and December 2015, at both the Unit of Internal Medicine and Cardiology of University and Hospital of Brescia. Enrolled subjects underwent a single visit where medical history and the subject's characteristics were collected. In the same visit respiratory function tests and PAT were recorded.

\section{2 | Subjects}

A total of 48 subjects were enrolled in the study: 16 consecutive patients with stable COPD, 16 consecutive patients with treated $\mathrm{AH}$ and 16 healthy subjects matched for age and sex. A study design powered at 0.80 requires 16 participants to detect a 0.40 change in RHI (Clin calc: sample size calculator, available on website http://clincalc.com/stats/samplesize. aspx) considering a normal standard deviation of 0.4. Diagnosis of COPD was based on the medical history and confirmed by pulmonary function test performed during the visit. Patients were classified by severity in four stages according to the Global Initiative for Chronic Obstructive Lung Disease (GOLD) criteria. ${ }^{10}$ Criteria for exclusion were the presence of one of the following characteristics: history of any cardiovascular disease (except $\mathrm{AH}$ ), diabetes mellitus, COPD exacerbation or respiratory infections in previous 6 months, diagnosis of asthma or other pulmonary diseases.

\section{3 | Study measurements}

Medical history, respiratory function tests, and PAT were recorded for each participant. Active smoking was defined if a current consumption of $>2$ cigarettes/day was reported; the number of pack/year was also recorded.

\subsection{1 | Blood pressure, heart rate and comorbidities}

Systemic AH was defined if assuming antihypertensive treatment, in the presence of a medical history with documented high blood pressure (BP), if systolic BP $>140 \mathrm{~mm} \mathrm{Hg}$ and/ or diastolic $\mathrm{BP}>90 \mathrm{~mm} \mathrm{Hg}$ on three separate occasions. ${ }^{11}$ Systolic (SBP), diastolic blood (DBP) pressure and heart rate (HR) were measured in the lying position, at one-minute intervals, on three occasions according to ESH-ESC guidelines (2003). ${ }^{11}$ The mean values of SBP, DBP and HR were reported. Coexisting chronic diseases were identified by examining the clinical documentation.

\subsection{2 | Respiratory function tests}

Lung spirometry was performed in accordance with the standard procedures. ${ }^{12}$ Forced Vital Capacity (FVC) and Forced Expiratory Volume in the first second $\left(\mathrm{FEV}_{1}\right)$ were recorded with the subject sitting, and the spirometry maneuver was repeated at least three times. The best results were 
collected. The percent-of-predicted values were calculated from the European Respiratory Society's standards data. ${ }^{13}$

\subsection{3 | Endothelial function}

PAT signals were obtained using the EndoPAT-2000 device (Itamar Medical Ltd, Caesarea, Israel), which has been validated and used previously to assess peripheral arterial tone in other populations. ${ }^{14-16}$ Specially designed finger probes are placed on the middle finger of each subject's hands. These probes comprised a system of inflatable latex air cuffs connected by pneumatic tubes to an inflating device controlled through a computer algorithm. A constant counter pressure (pre-determined by baseline diastolic blood pressure) is applied through the air cushions, this prevents venous pooling, thus avoiding venous-arteriolar reflex vasoconstriction, with no occlusion of arterial blood flow. Pulsate volume changes of the distal digit induce pressure alterations in the finger cuff, which are sensed by pressure transducers and transmitted to and recorded by the EndoPAT-2000 device. A decrease in the arterial blood volume in the distal fingertip causes a decrease in pulsatile arterial column changes, reflected as a decrease in the measured PAT signal, and vice versa. Endothelial function is measured via a reactive hyperemia $(\mathrm{RH})$ protocol: it consists of a 5 minutes baseline measurement, after which a blood pressure cuff on the test arm is inflated to $60 \mathrm{~mm} \mathrm{Hg}$ above baseline systolic BP or at least $200 \mathrm{~mm} \mathrm{Hg}$ for 5 minutes. Occlusion of pulsate arterial flow is confirmed by the reduction of the PAT tracing to zero. After 5 minutes, the cuff is deflated, and the PAT tracing is recorded for a further 5 minutes. The ratio of the PAT signal after cuff release compared with baseline is calculated through a computer algorithm automatically normalizing for baseline signal and indexed to the contra lateral arm. The calculated ratio is called RH-PAT index or RH index (RHI). Its normal value is $>2.00$ (pure number), while a clear endothelial dysfunction is shown by a value $\leq 1.67$ as recommended cutoff value in the user manual of the EndoPAT 2000 device, gathered from clinical data. ${ }^{17}$ The EndoPAT test is both operator and interpreter independent. ${ }^{18,19}$

\subsection{4 | Statistical analysis}

Data were presented as mean \pm standard deviation (SD) or Confidential Intervals 95\% [CI 95\%]. Logarithmic transformation of RHI was used (LnRHI). Subjects were analysed according to different groups (COPD, treated AH patients and Controls) or categories (presence of endothelial dysfunction value $\mathrm{RHI} \leq 1.67(\mathrm{LnRHI} \leq 0.51)$ as the median cut-off of distribution, presence of $\mathrm{AH}$ ).

After verifying that data were normally distributed, group comparisons of mean values were performed using $t$ test for independent variables. If data were not normally distributed non-parametrical analysis was performed. Analysis of correlation among variables was performed by multiple regression. Categorical variables were compared by using the chisquare test method. A $P$ value $<.05$ was considered to be significant. All analyses were performed with the dedicated software (SPSS 21.0 for Windows; SPSS, Chicago, Illinois).

\section{3 | RESULTS}

\section{1 | Patients}

Demographic and clinical characteristics of subjects studied are reported in Table 1: groups were matched for age, sex and body mass index (BMI). The control group showed more non-smoking subjects compared to the other groups. No differences among the studied groups were observed for BP data. COPD patients showed impaired $\mathrm{FEV}_{1}$ and FEV1/ FVC mean data as expected. A summary of the taken medications in the different studied groups was reported in Table 2. No significant differences in the taken medications were seen between the group of COPD and patients with treated $\mathrm{AH}$.

\section{2 | Endothelial function}

The prevalence of endothelial dysfunction $(\mathrm{LnRHI} \leq 0.51)$ was significantly higher in COPD group than in the other groups $(75 \% ; 43 \%$ and none in COPD, $\mathrm{AH}$ and controls, respectively; $P<.01$ ). Mean LnRHI was significantly lower in COPD patients compared with the value found in the other groups $(0.27 \pm 0.52 ; 0.63 \pm 0.33 ; 0.85 \pm 0.13$ in COPD, $\mathrm{AH}$ and controls, respectively; $P<.01)$ as reported in Figure 1. It is important to underline that subjects in the group of $\mathrm{AH}$ showed intermediate levels of LnRHI significantly different form COPD levels (lower) and control levels (higher). At linear regression $\mathrm{FEV}_{1}$ and LnRHI were directly correlated (Figure 2) showing a Spearman index $=0.553(P=.026)$ (Figure 2). Analysing data according GOLD stages showed that patients in groups $\mathrm{C}$ and $\mathrm{D}$ (eight patients) showed lower LnRHI compared with eight patients classified as A and B $(0.59 \pm 0.37$ and $-0.42 \pm 0.47$, respectively; $P<.01)$

At multiple regression analysis the presence of dyslipidemia, COPD and AH were associated with the presence of endothelial dysfunction: Odd Risk [CI95\%] for endothelial dysfunction if presence of dyslipidemia $=15.0$ [2.7-81.7]; if presence of COPD $=10.7$ [2.6-43.8]: if presence of $\mathrm{AH}=40.0$ [4.6-347.5]. According to this analysis LnRHI was lower in patients with both COPD and AH. The number of COPD exacerbations in the year before the study, and all the other studied variables were not found significantly correlated with LnRHI. 
TABLE 1 Demographic, clinical and functional characteristics of patients studied

\begin{tabular}{|c|c|c|c|c|}
\hline Group & COPD $n=16$ & Treated AH $(n=16)$ & Controls $(n=16)$ & $P$ \\
\hline BMI & $26.1 \pm 3.7$ & $27.2 \pm 3.5$ & $24.1 \pm 2.7$ & n.s. \\
\hline Smoking & & & & $<.01$ \\
\hline Current & 3 & 4 & 3 & \\
\hline No & 6 & 7 & 10 & \\
\hline Packs/year & $34 \pm 11$ & $30 \pm 8$ & $31 \pm 7$ & n.s. \\
\hline Arterial pressure systolic & $130.3 \pm 18.0$ & $129.1 \pm 9.5$ & $125.8 \pm 7.0$ & n.s. \\
\hline Arterial pressure diastolic & $79.0 \pm 10.8$ & $77.5 \pm 9.4$ & $75.6 \pm 7.8$ & n.s. \\
\hline $\mathrm{FEV}_{1}(\%$ pred.) & $69.5 \pm 19.0$ & $110 \pm 15.0$ & $105 \pm 12.3$ & $<.01$ \\
\hline $\mathrm{FEV}_{1} / \mathrm{FVC}$ & $66.1 \pm 11.5$ & $96 \pm 10.0$ & $98 \pm 20.2$ & $<.01$ \\
\hline
\end{tabular}

Abbreviations: AH, arterial hypertension; BMI, body max index; COPD, chronic obstructive pulmonary disease; FEV1, forced exhaled volume at first second; FVC, forced vital capacity; n.s., not significant; pred., predicted.

Data expressed as mean \pm standard deviation or frequency.

\section{4 | DISCUSSION}

The study data showed a higher prevalence of endothelial dysfunction measured with RH-PAT in stable COPD patients compared to controls and treated hypertensive patients. The severity of RHI impairment was higher in stable COPD subjects compared with the other groups and was related to the degree of $\mathrm{FEV}_{1}$ reduction. $\mathrm{AH}$ and COPD seems to be independently related to endothelial dysfunction. Differences in LnRHI observed comparing stable COPD and treated AH

TABLE 2 Treatments of COPD and AH groups during the study

\begin{tabular}{lll} 
Group & COPD $\mathbf{n}=\mathbf{1 6}$ & AH $(\mathbf{n}=\mathbf{1 6})$ \\
\hline Beta blockers & 4 & 6 \\
\hline Antiaggregants & 7 & 7 \\
\hline ACE inhibitors/sartans & 8 & 10 \\
\hline Statins & 5 & 4 \\
\hline Calcium blockers & 5 & 6 \\
\hline Diuretics & 4 & 2 \\
\hline
\end{tabular}

Abbreviations: ACE, angiotensin-converting-enzyme; AH, arterial hypertension; COPD, chronic obstructive pulmonary disease. patients should not be attributable to different treatments because the two groups were similar with respect to the drug management. Previous studies found a correlation between the presence of endothelial dysfunction and $\mathrm{COPD}^{6,8,20-24}$ using various techniques and among these only one study

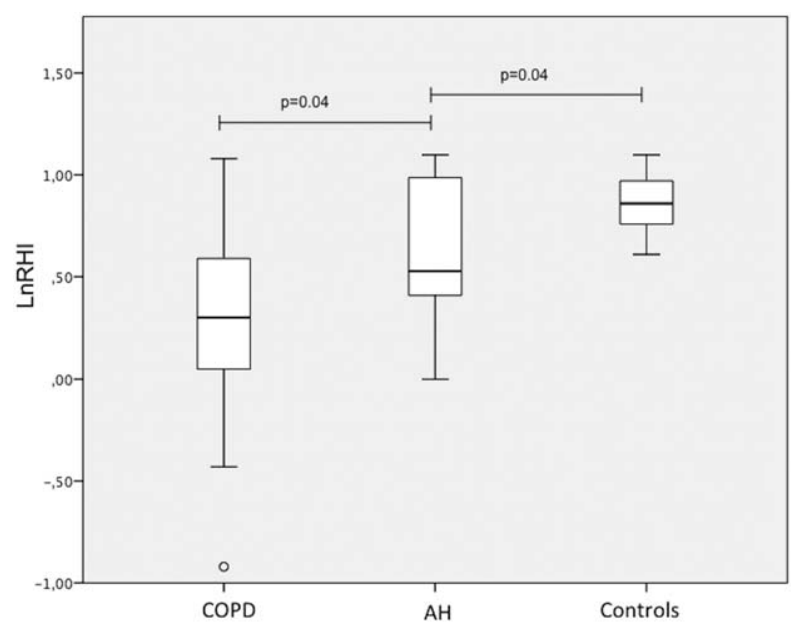

FIGURE 1 Mean LnRHI (reactive hyperemia index) in the three studied groups. (COPD, chronic obstructive pulmonary disease; $\mathrm{AH}$, arterial hypertension; Thick line showing median, Box showing 25\% and 75\% inter-quartile ranges and error bars showing minimum and maximum values. The little circle indicates an outliner value) 


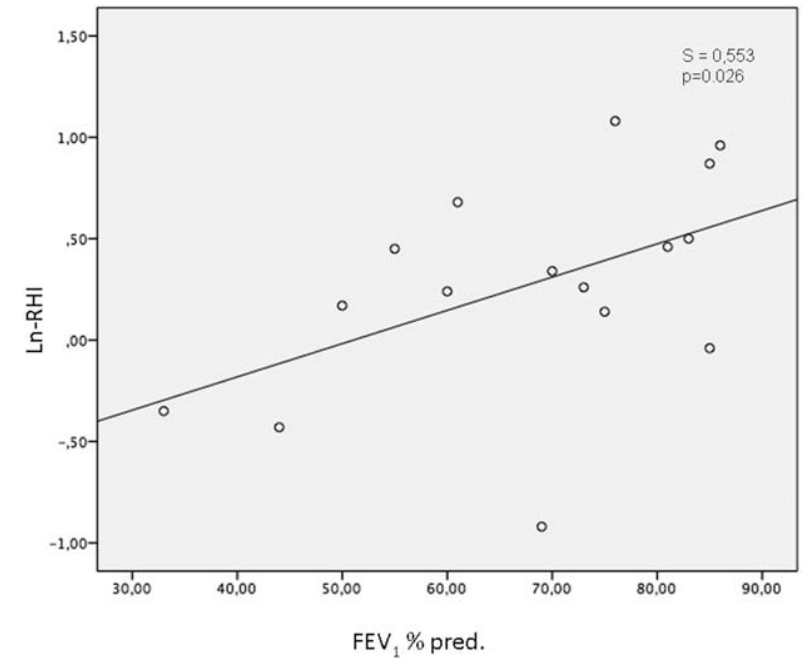

FIGURE 2 Correlation between $\mathrm{FEV}_{1}$ (forced exhaled volume at first second) and LnRHI (reactive hyperemia index) in patients with stable $\mathrm{COPD}$ (S, spearman index; pred., predicted)

using the PAT method. ${ }^{25}$ In literature RH-PAT measurements allow to quantify cardiovascular risk ${ }^{18}$ and predict late adverse cardiovascular events. ${ }^{19}$ The main well known contributing factors for endothelial dysfunction are $\mathrm{AH}$, chronic inflammation, and oxidative stress and metabolic disorders. ${ }^{26}$ Bronchial obstruction and bronchial inflammation are strictly related in $\mathrm{COPD}^{27}$ and bronchial inflammation, is associated with systemic inflammation. ${ }^{28}$ Smoking may act through different factors in the development of endothelial dysfunction by altering the balance between oxidants and antioxidants, reducing the production of exhaled nitric oxide and promoting the release of mediators of inflammation and acute phase proteins. All these factors are able to alter the endothelial homeostasis. ${ }^{29}$ The correlation between the degree of bronchial obstruction and endothelial dysfunction was constantly observed in previous studies ${ }^{6,8,20-24}$ and can be explained by the effects of several factors such as hypoxemia acting through the production of inflammatory cytokines and increasing oxidative stress. ${ }^{30}$ In addition, the increase in heart rate and blood pressure and the activation of the reninangiotensin-aldosterone system play a role in the development of endothelial dysfunction induced in COPD with severe disease. $^{30}$

\section{1 | Study limitations}

The small number of subjects in the three groups did not allow a proper analysis of the subpopulations and especially for the influences of the different medications taken. However, the groups appear to be sufficiently homogeneous to obtain a meaningful comparison. Another limiting factor is the presence of many non-smokers subjects in the control group, although according to the analysis of logistic regression smoking is not found to be meaningfully associated with endothelial dysfunction in our study sample. It should be noted that the endothelial dysfunction should be particularly affected by the current smoking habit while in the groups analysed active smokers were equally distributed. The arterial blood gas values and data on oxidative stress or inflammation have not been assessed as this was beyond the objective of the study. Finally a comparison with other detection techniques of endothelial dysfunction such as PWV has not been performed, this could have been an interesting analysis from a methodological standpoint.

\section{5 | CONCLUSIONS}

Firstly the presence of endothelial dysfunction in patients with stable COPD independently from high blood pressure values is probably implicated in the frequent cardiovascular comorbidity typical of these patients. Secondly the analysis of endothelial dysfunction, with simple technique such as RH-PAT, gave results consistent with those obtained through more complex techniques such as the PWV and the FMD. The results of the present study suggest the potential utility of endothelial dysfunction evaluation in patients with COPD, in particular the presence of endothelial dysfunction should suggest a more timely evaluation and treatment for CAD. Nevertheless, additional long-term studies are needed to establish the clinical impact of this technique on COPD patients.

\section{CONFLICT OF INTEREST}

The authors have stated explicitly that there are no conflicts of interest in connection with this article.

\section{AUTHOR CONTRIBUTIONS}

All the authors read and approved the manuscript.

Study conception: Malerba, Radaeli, Vizzardi

Collected data: Sciatti, Salghetti.

Analyzed data: Bonadei, Platto

Revised data analysis: Carpagnano, Clini

Wrote manuscript: Malerba, Radaeli, Nardin

\section{ETHICS}

The study was conducted in accordance with the precepts of the Helsinki Declaration, and all data were handled anonymously accordingto the ethical committee.

\section{OR CID}

Mario Malerba (D) http://orcid.org/0000-0001-7789-2359 


\section{REFERENCES}

[1] Qureshi H, Sharafkhaneh A, Hanania NA. Chronic obstructive pulmonary disease exacerbations: latest evidence and clinical implications. Ther Adv Chronic Dis. 2014;5(5):212-227. https:// doi.org/10.1177/2040622314532862.

[2] Barnes PJ, Celli BR. Systemic manifestations and comorbidities of COPD. Eur Respir J. 2009;33(5):1165-1185. https://doi.org/ 10.1183/09031936.00128008.

[3] Lange P, Mogelvang R, Marott JL, Vestbo J, Jensen JS. Cardiovascular morbidity in COPD: a study of the general population. COPD. 2010;7(1):5-10. https://doi.org/10.3109/1541255090 3499506.

[4] Patel ARC, Kowlessar BS, Donaldson GC, et al. Cardiovascular risk, myocardial injury, and exacerbations of chronic obstructive pulmonary disease. Am J Respir Crit Care Med. 2013;188(9): 1091-1099. https://doi.org/10.1164/rccm.201306-1170OC.

[5] Deanfield JE, Halcox JP, Rabelink TJ. Endothelial function and dysfunction: testing and clinical relevance. Circulation. 2007;115 (10):1285-1295. https://doi.org/10.1161/CIRCULATIONAHA.106. 652859.

[6] Barr RG, Mesia-Vela S, Austin JHM, et al. Impaired flowmediated dilation is associated with low pulmonary function and emphysema in ex-smokers: the Emphysema and Cancer Action Project (EMCAP) Study. Am J Respir Crit Care Med. 2007;176(12):1200-1207. https://doi.org/10.1164/rccm.20070 7-980OC.

[7] Clarenbach CF, Senn O, Sievi NA, et al. Determinants of endothelial function in patients with COPD. Eur Respir J. 2013;42(5):1194-1204. https://doi.org/10.1183/09031936.00 144612 .

[8] Eickhoff P, Valipour A, Kiss D, et al. Determinants of systemic vascular function in patients with stable chronic obstructive pulmonary disease. Am J Respir Crit Care Med. 2008;178(12):1211-1218. https://doi.org/10.1164/rccm.20070 9-1412OC.

[9] Lekakis J, Abraham P, Balbarini A, et al. Methods for evaluating endothelial function: a position statement from the European Society of Cardiology Working Group on Peripheral Circulation. Eur J Cardiovasc Prev Rehabil. 2011;18(6):775-789. https://doi. org/10.1177/1741826711398179.

[10] Global Initiative for Chronic Obstructive Lung Disease (GOLD). GOLD 2017 global strategy for the diagnosis, management, and prevention of chronic obstructive pulmonary disease, update 2017 report. Available at http://goldcopd.org/gold-2017-global-strategydiagnosis-management-prevention-copd/. Accessed March 27, 2017.

[11] European Society of Hypertension-European Society of Cardiology Guidelines Committee. 2003 European Society of Hypertension-European Society of Cardiology guidelines for the management of arterial hypertension. J Hypertens. 2003;21 (6):1011-1053. https://doi.org/10.1097/01.hjh.0000059051.65 882.32.

[12] Standardization of Spirometry, 1994 Update. American Thoracic Society. Am J Respir Crit Care Med. 1995;152(3):1107-1136. https://doi.org/10.1164/ajrccm.152.3.7663792.

[13] Quanjer PH, Tammeling GJ, Cotes JE, Pedersen OF, Peslin R, Yernault JC. Lung volumes and forced ventilatory flows. Eur
Respir J. 1993;6(suppl 16):5-40. https://doi.org/10.1183/ $09041950.005 \mathrm{~s} 1693$.

[14] Goor D.A, Sheffy J, Schnall RP, et al. Peripheral arterial tonometry: a diagnostic method for detection of myocardial ischemia induced during mental stress tests: a pilot study. Clin Cardiol. 2004;27(3): 137-141. http://www.ncbi.nlm.nih.gov/pubmed/15049379.

[15] Bonetti PO, Barsness GW, Keelan PC, et al. Enhanced external counterpulsation improves endothelial function in patients with symptomatic coronary artery disease. J Am Coll Cardiol. 2003; 41:1761-1768. https://doi.org/10.1016/S0735-1097(03)00329-2.

[16] Bonetti PO, Lerman LO, Lerman A. Endothelial dysfunction: a marker of atherosclerotic risk. Arterioscler Thromb Vasc Biol. 2003;23(2):168-175. https://doi.org/10.1161/01.ATV.000005138 4.43104.FC.

[17] Bonetti PO, Pumper GM, Higano ST, Holmes DR, Kuvin JT, Lerman A. Noninvasive identification of patients with early coronary atherosclerosis by assessment of digital reactive hyperemia. J Am Coll Cardiol. 2004;44(11):2137-2141. https://doi.org/ 10.1016/j.jacc.2004.08.062.

[18] Hamburg NM, Keyes MJ, Larson MG, et al. Cross-sectional relations of digital vascular function to cardiovascular risk factors in the Framingham heart study. Circulation. 2008;117(19): 2467-2474. https://doi.org/10.1161/CIRCULATIONAHA.107. 748574.

[19] Rubinshtein R, Kuvin JT, Soffler M, et al. Assessment of endothelial function by non-invasive peripheral arterial tonometry predicts late cardiovascular adverse events. Eur Heart J. 2010;31(9):1142-1148. https://doi.org/10.1093/ eurheartj/ehq010.

[20] Maclay JD, McAllister DA, Rabinovich R, et al. Systemic elastin degradation in chronic obstructive pulmonary disease. Thorax. 2012;67(7):606-612. https://doi.org/10.1136/thoraxjnl2011-200949.

[21] Cinarka H, Kayhan S, Gumus A, et al. Arterial stiffness measured via carotid femoral pulse wave velocity is associated with disease severity in COPD. Respir Care. 2014;59(2):274-280. https://doi.org/10.4187/respcare.02621.

[22] Vivodtzev I, Minet C, Tamisier R, et al. Arterial stiffness by pulse wave velocity in COPD: reliability and reproducibility. Eur Respir J. 2013;42(4):1140-1142. https://doi.org/10.1183/ 09031936.00014813.

[23] Mills NL, Miller JJ, Anand A, et al. Increased arterial stiffness in patients with chronic obstructive pulmonary disease: a mechanism for increased cardiovascular risk. Thorax. 2008;63(4):306311. https://doi.org/10.1136/thx.2007.083493.

[24] Duckers JM, Shale DJ, Stockley RA, et al. Cardiovascular and musculoskeletal co-morbidities in patients with alpha 1 antitrypsin deficiency. Respir Res. 2010;11:173. https://doi.org/10.1186/ 1465-9921-11-173.

[25] Minet C, Vivodtzev I, Tamisier R, et al. Reduced six-minute walking distance, high fat-free-mass index and hypercapnia are associated with endothelial dysfunction in COPD. Respir Physiol Neurobiol. 2012;183(2):128-134. https://doi.org/10.1016/j.resp. 2012.06.017.

[26] Maclay JD, MacNee W. Cardiovascular disease in COPD. Chest. 2013;143(3):798-807. https://doi.org/10.1378/chest.12-0938. 
[27] Soler N, Ewig S, Torres A, Filella X, Gonzalez J, Zaubet A. Airway inflammation and bronchial microbial patterns in patients with stable chronic obstructive pulmonary disease. Eur Respir J. 1999;14(5):1015-1022.

[28] Gan WQ, Man SFP, Senthilselvan A, Sin DD. Association between chronic obstructive pulmonary disease and systemic inflammation: a systematic review and a meta-analysis. Thorax. 2004;59(7):574-580.

[29] Boschetto P, Beghé B, Fabbri LM, Ceconi C. Link between chronic obstructive pulmonary disease and coronary artery disease: implication for clinical practice. Respirology. 2012;17(3): 422-431. https://doi.org/10.1111/j.1440-1843.2011.02118.x.
[30] Vivodtzev I, Tamisier R, Baguet J-P, Borel JC, Levy P, Pépin J-L. Arterial stiffness in COPD. Chest. 2014;145(4):861-875. https://doi.org/10.1378/chest.13-1809.

How to cite this article: Malerba M, Radaeli A, Nardin M, et al. Endothelial dysfunction assessment by noninvasive peripheral arterial tonometry in patients with chronic obstructive pulmonary disease compared with healthy subjects. Clin Respir J. 2018;12:14661472. https://doi.org/10.1111/crj.12686 